1

\title{
Hypogonadism in Prader-Willi syndrome from birth to adulthood: a 28-year experience in a single centre
}

\author{
Sakina Kherra', Wendy Forsyth Paterson², Filiz Mine Cizmecioglu ${ }^{3}$, Jeremy Huw Jones ${ }^{1}{ }^{4}$, Mariam Kourime ${ }^{5}$, \\ Heba Hassan Elsedfy ${ }^{6}$, Sameh Tawfik ${ }^{7}$, Andreas Kyriakou4 ${ }^{4}$, Mohamad Guftar Shaikh ${ }^{4}$ and \\ Malcolm David Cairns Donaldson (D8) \\ ${ }^{1} \mathrm{CHU}$ Parnet Hopital, Algiers, Algeria \\ ${ }^{2}$ Royal Hospital for Sick Children, Yorkhill, Glasgow, UK \\ ${ }^{3}$ Paediatric Endocrinology and Diabetes Department, Kocaeli University, Kocaeli, Turkey \\ ${ }^{4}$ Department of Pediatric Endocrinology, Royal Hospital for Children Glasgow, NHS Greater Glasgow and Clyde, Glasgow, UK \\ ${ }^{5}$ Abderrahim Harouchi Hôpital, Casablanca, Morocco \\ ${ }^{6}$ Pediatrics Department, Ain Shams University, Cairo, Egypt \\ ${ }^{7}$ Department of Pediatrics, Maadi Hospital, Cairo, Egypt \\ ${ }^{8}$ Section of Child Health, Glasgow University School of Medicine, Glasgow, UK
}

Correspondence should be addressed to M D C Donaldson: malcolm.donaldson@glasgow.ac.uk

\section{Abstract}

Background: Hypogonadism is a key feature of Prader-Willi syndrome (PWS) but clear strategies for hormone replacement are lacking.

Objective: To evaluate the gonadal status and outcome in patients attending a Scottish PWS clinic from 1991 to 2019.

Methods: In 93 (35F:56M) patients, median follow-up 11.2 years, gonadal and pubertal status were assessed clinically. Pelvic ultrasound findings and basal/stimulated gonadotrophins were compared with age-matched controls.

Results: Females: of 22 patients aged > 11, 9 had reached B4-5, while 5 were still at B2-3, and 6 remained prepubertal. Eight patients experienced menarche aged 9.8-21.4 years, none with a normal cycle. Uterine length and ovarian volumes were normal but uterine configuration remained immature, with low follicular counts. Gonadotrophins were unremarkable, serum oestradiol 129 (70-520) pmol/L. Only 5 patients received oestrogen replacement. Males: fifty-four (96\%) patients were cryptorchid ( 9 unilateral). Weekly hCG injections resulted in unilateral/bilateral descent in 2/1 of 25 patients. Of 37 boys aged $>11,14$ ( 9 with failed/untreated bilateral cryptorchidism) failed to progress beyond G1, 15 arrested at G2-3 (testes 3-10 mL), and 8 reached G4-5. Gonadotrophins were unremarkable except in boys at G2-5 in whom FSH was elevated: $12.3 / 27.3$ vs $3.25 / 6.26 \mathrm{U} / \mathrm{L}$ in controls $(P<0.001)$. In males aged $>13$, testosterone was $3.1(0.5-8.4)$ $\mathrm{nmol} / \mathrm{L}$. Androgen therapy, given from 13.5 to 29.2 years, was stopped in $4 / 24$ patients owing to behavioural problems.

Conclusion: Despite invariable hypogonadism, few females and only half the males with PWS in this study received hormone replacement. Double-blind placebo-controlled crossover trials of sex steroids are required to address unproven behavioural concerns.

\section{Key Words}

- Prader-Willi syndrome

- central hypogonadism

- primary hypogonadism

- cryptorchidism

- orchidopexy

- pelvic ultrasound

- gonadotrophins

- human chorionic gonadotrophin

- puberty

- oestrogen therapy

- testosterone therapy https://ec.bioscientifica.com https://doi.org/10.1530/EC-21-0277 (c) 2021 The authors Published by Bioscientifica Ltd

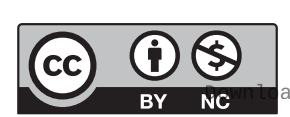

This work is licensed under a Creative Commons Attribution-NonCommercial 4.0 International License. ded from Bioscientifica.com at 04/26/2023 04:25:17AM
Endocrine Connections (2021) 10, 1134-1146 


\section{Introduction}

The Prader-Willi syndrome (PWS) results from the absence of paternally imprinted genes in the 15q 11-13 region, caused by a deletion in the paternal chromosome (del15q) in $70 \%$ of cases and disomy of the maternal chromosome (mUPD15) in about 25\% (1). Rarer causes include imprinting centre mutations (2) and unbalanced translocation/deletions involving the critical region of $15 \mathrm{q}(3)$.

PWS is a neurodevelopmental disorder with a particular impact on the hypothalamus. Key features include hypotonia, hyperphagic obesity, mild-tomoderate learning disability, major behaviour difficulties, impaired linear growth, and hypogonadism $(4,5,6)$. Full independent living in adulthood is precluded by the behaviour difficulties and hyperphagia which, when unchecked, results in morbid obesity with type 2 diabetes and death from respiratory failure and skin sepsis $(5,6)$.

The profile of hypogonadism in PWS males has been well documented $(7,8,9,10,11,12)$. Clinical features include small penis, scrotal hypoplasia and cryptorchidism at birth, with spontaneous puberty but mid-pubertal arrest and reduced testicular volume attributable to a reduction in seminiferous tubules. Basal gonadotrophins and testosterone levels during early childhood are unremarkable, with preservation of minipuberty (13) but inhibin B levels wane from 10 years onwards $(7,8,9)$. Testosterone levels are low during and after puberty, and basal FSH is elevated in some but not all pubertal and adult patients $(7,8,9,10)$. Testicular histology in adults is variable (10) with no reports of male fertility.

Fewer centres have reported on females with hypogonadism $(8,11,14,15)$. Features include hypoplastic labia at birth, normal age of pubertal onset but delayed although usually complete secondary sexual development and invariable oligo-amenorrhoea. Longitudinal basal gonadotrophin, anti-Müllerian hormone $(\mathrm{AMH})$ and inhibin B from birth to adulthood are usually within the population range, but oestradiol levels during and after puberty are low (15).

For three decades, we have held a multidisciplinary PWS clinic in Glasgow (5), using pelvic ultrasonography, gonadotrophin stimulation testing and human chorionic gonadotrophin (hCG) stimulation in the assessment of our patients, whose mean duration of follow-up is nearly 15 years. The purpose of this paper is to report on the outcome in our patients and discuss optimal management of hypogonadism, including cryptorchidism and sex hormone replacement therapy.

\section{Patients and methods}

At the inception of the Glasgow PWS clinic in 1991, the focus was initially on diagnosis, separating PWS patients from those with other causes of learning disability and obesity by using the Holm criteria (4) combined with newly established methylation testing techniques for $15 \mathrm{q}$ analysis (16).

Until 2011, clinical, biochemical, pelvic ultrasound and surgical treatment details on PWS patients were collected on a rolling basis by our auxologist, Wendy Paterson, who also logged information on patients attending the hospital between 1974 and 1991. After her untimely death in 2012, data collection was relaunched in 2015 and finalised in 2019.

Pubertal staging was carried out according to the method of Tanner (17) and menstrual history was recorded. Staging in girls and women was carried out mainly by WFP from 1991 to 2011, or by our specialist endocrine nurse from 1995 until the end of the study period. Testicular position and volume were assessed both clinically and from surgical operation notes.

A pelvic ultrasound service was established in 1990, with normative data established in girls aged $\leq 15$ years (18). Transabdominal pelvic ultrasound examination was performed using an Acuson 128 XP10 system (Mountain View, CA, USA) with a 5 - or $7-\mathrm{MHz}$ sector probe. Uterine length and ovarian volumes were plotted onto normative centile charts. The number and size of ovarian follicles between 2 and $10 \mathrm{~mm}$ diameter, and the number measuring $>10 \mathrm{~mm}$ was recorded. Uterine shape was classified as infantile (cervix wider than fundus), cylindrical (cervical and fundal depth approximately equal), or pubertal (fundal depth $>$ cervical depth) and also expressed as the fundal-cervical ratio (FCR). Uterine length in older patients was compared with the normative data for nulliparous women aged 25 years (19). Endometrial thickness was recorded, and the values detected were compared with the normative data of Gilligan et al. (20).

Luteinising hormone (LH) and follicle-stimulating hormone (FSH) were measured using an Abbott AxSYM from 1990 until 2004, by DPC Immulite 2000 (Siemens) until 2014 and Abbott Architect immunoassay thereafter. Testosterone and oestradiol were measured at Glasgow Royal Infirmary, by RIA until 2013 and since then by liquid chromatography-mass spectrometry (LC-MS). In 2000, inhibin B was measured in male patients in a single batch run using a double antibody ELISA, as previously described (21). Inhibin B in females and sex hormone-binding globulin (SHBG) and anti-Mullerian hormone (AMH) in

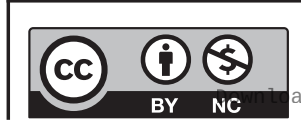

This work is licensed under a Creative Commons Attribution-NonCommercial 4.0 International License. ded from Bioscientifica.com at 04/26/2023 04:25:17AM 
both sexes were not measured sufficiently regularly to be analysed in this study.

Assay detection limits for LH and FSH were $<0.5 \mathrm{U} / \mathrm{L}$ until 2010, <0.1 from 2010 to 2014, and $<0.2$ from 2015. Detection limits were $<0.5 \mathrm{nmol} / \mathrm{L}$ for testosterone, $<70 \mathrm{pmol} / \mathrm{L}$ for oestradiol and $8 \mathrm{ng} / \mathrm{L}$ for inhibin $\mathrm{B}$. Gonadotrophin stimulation tests were performed using $100 \mu \mathrm{g}$ of LHRH (Relefact LH-RH-Hoechst Marion Rousse) and peak LH and FSH values at 30 and 60 min recorded. Stimulation tests were always carried out between 09:00 and 11:00 $\mathrm{h}$ but basal hormone measurements taken in the clinic could be either in the morning or afternoon.

Normative data from 85 subjects undergoing investigation by the same laboratory, usually for short stature and delayed puberty, in whom no endocrine abnormality was found are shown in Table 1 and are used for comparison.

hCG (Profassi (Serono) or Pregnyl (Organon)) was given as a single intramuscular injection (usually 5000 units) or for 4-5 days (usually 1500-2000 units) to test Leydig cell reserve from 1982 to 1995 . Thereafter, it was largely superseded by twice-weekly hCG, usually 1500 2000 units, for 3-6 weeks to promote testicular descent.

\section{Data analysis}

Biochemical data are presented according to specified age bands, using one data point per patient per age band. In patients with more than one point per age band, data were selected from the age closest to the mid-point, with priority given to pelvic ultrasound measurements in which the ovaries had been visualised, and in biochemical tests where an LHRH test had been carried out. For statistical purposes, gonadotrophin values of $<0.2$ or $<0.5 \mathrm{U} / \mathrm{L}$ were evaluated as if at the limit of detection.

All statistical analyses were done using Minitab (version 19) at a significance level of $5 \%$ for data sets where $n=5$ or greater. Data distribution was assessed for normality using Anderson-Darling test. Parametric data are presented as mean ( \pm S.D.) and non-parametric data as median (range). Quantitative variables were compared using $t$-tests and ANOVA or Kruskal-Wallis and Mann-Whitney tests, as appropriate. Qualitative variables were compared using chi-squared or Fisher's exact tests.

\section{Ethical aspects}

Approval was initially granted by the Ethical Committee of the Royal Hospital for Sick Children in Glasgow in 2004 and data collection was initially completed in 2011. The second phase of the study was approved by the NHS Research Ethics Authority (reference 15/NW/0900). In 2019, the current status of patients, where available, was assessed via Clinical Portal (https://www.ggc-clinicalportal.scot.nhs. uk/concerto). Consent was obtained from each patient and family after a full explanation of the purpose and nature of all procedures used.

\section{Results}

Between 1991 and 2019, a total of 93 patients (37 females, 56 males), born between 1950 and 2016, were seen in the multidisciplinary PWS clinic (Table 2). Deaths were recorded in 11 patients (3 female), 9 with complications

Table 1 Reference data for gonadotrophins from the Department of Biochemistry, Royal Hospital for Sick Children, Glasgow before (basal) and after (peak) stimulation with $100 \mathrm{mg}$ intravenous LHRH, derived from 85 subjects, aged 3-17 years, with no evidence of endocrine disease. Reference data for serum testosterone and oestradiol are from the Institute of Biochemistry, Glasgow Royal Infirmary.

\begin{tabular}{|c|c|c|c|c|c|c|}
\hline Tanner stage & Basal LH, U/L & Peak LH, U/L & Basal FSH, U/L & Peak FSH, U/L & Testosterone, $\mathrm{nmol} / \mathrm{L}$ & Oestradiol, pmol/L \\
\hline \multicolumn{7}{|l|}{ Girls } \\
\hline $\mathrm{B} 1(n=21)$ & $0.5(<0.2-2.4)$ & $1.95(0.5-4.7)$ & $2.0(<0.2-5)$ & $11.6(2.2-26.4)$ & & \\
\hline $\mathrm{B} 2(n=4)$ & $0.5(0.3-2.6)$ & $8.9(1.4-12.5)$ & $3.7(0.5-8.9)$ & $13.15(6.8-22.2)$ & & \\
\hline B3-5 $(n=5)$ & $1.0(0.7-1.8)$ & $14.3(6.1-31.9)$ & $5.5(1.7-6.9)$ & $13.8(7-15.6)$ & & $70(40-300)$ \\
\hline \multicolumn{7}{|l|}{ Boys } \\
\hline $\mathrm{G} 1(n=43)$ & $0.5(<0.2-1)$ & $1.6(0.5-8.8)$ & $0.85(<0.2-3.4)$ & $4.4(0.9-11.6)$ & $0.4(<0.3-1.3)$ & \\
\hline $\mathrm{G} 2(n=9)$ & $0.8(<0.2-2)$ & $8.1(3.3-13.6)$ & $1.7(0.3-4.2)$ & $2.6(0.9-11.2)$ & $0.9(0.7-11.2)$ & \\
\hline G3-5 $(n=6)$ & $1.9(1.9-4)$ & $22.3(16.4-27.2)$ & $3.2(1.8-10.6)$ & $6.45(2.8-17)$ & $13.2(8.3-17.2)$ & \\
\hline \multicolumn{7}{|l|}{ Adult } \\
\hline & & & & & $8.7-35$ & $180-1500$ \\
\hline
\end{tabular}

$\mathrm{B}$, breast stage; FSH, follicle-stimulating hormone; G, genital stage of puberty according to Tanner; LH, luteinising hormone; LHRH, luteinising hormone releasing hormone.

https://ec.bioscientifica.com https://doi.org/10.1530/EC-21-0277 (c) 2021 The authors Published by Bioscientifica Ltd

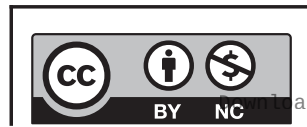

This work is licensed under a Creative Commons Attribution-NonCommercial 4.0 International License. ded from Bioscientifica.com at 04/26/2023 04:25:17AM via free access 
of morbid obesity aged $26(17.8-40)$ years, while a woman died unexpectedly at 44 years with pneumonia, and a boy aged 14.4 years died with complications of extra-hepatic portal hypertension which were unrelated to PWS. Ten patients were lost to follow-up. Death rates before and after excluding the 10 patients lost for follow-up were 11/93 $(11.8 \%)$ and $11 / 83$ (13.2\%). After excluding 15 patients seen on fewer than three occasions, the mean duration of follow-up was 14.8 years. Neonatal details of the cohort have already been presented elsewhere (22). Mean birthweight was significantly reduced at $2.69 \mathrm{~kg}(n=87)$ compared to 3.33-3.4 kg for the Scottish population from 1980 to 2003.

Peak growth hormone levels were $4.9(0.03-26.0) \mu \mathrm{g} / \mathrm{L}$ $(n=31)$, with 8 and 11 values $<3$ and 3-7 $\mu \mathrm{g} / \mathrm{L}$, respectively. Growth hormone treatment was given to $20 / 55$ patients born before the year 2000 and 22/38 born from 2000 onwards. No patient received thyroxine. Obesity status at the most recent visit is shown in Table 2. Fourteen patients had developed type 2 diabetes, the youngest from 14 years. Significant psychiatric problems had been recorded in 22 (31\%) of the 72 patients who were aged 13 years by the end of the study.

\section{Gonadal status females}

\section{Clinical features}

Hypoplastic labia majora was poorly documented, being recorded in 6 of only 12 patients examined. Ages at reaching B2 and B5 were 12.2 (7.2-14.8) $(n=13)$ and $16.1(14.6-8.4)$ $(n=7)$ years. Two girls showed early breast development including one aged 7.2 years with B2 development, prepubertal LHRH test and pelvic ultrasound and a second with true puberty at 9.8 years - Tanner stage B3P2A2, menarche and basal/peak LH 4.2/32.8 U/L.

Of 28 patients aged $\geq 11$ years at last review, 9 women were at B4-5, 4 still B3 (aged 13.8-21.8 years), 3 still B2 (aged 12.4-13.6 years), 6 still B1 (aged 11-17.5 years), no data in 6. Spontaneous menarche had been recorded in 8 patients (2 at B3, 6 at B5) aged 17 (9.8-21.4) years, with no menses in 13, of whom 2 were below 13 years and 11 were 17.1 (13.8-46.8) years at last review, no data in 7. No patient had a normal cycle, with only 1 recorded period in 2 , and $\leq 4$ periods/year in the remaining patients.

\section{Pelvic ultrasound findings}

Figure $1 \mathrm{~A}, \mathrm{~B}, \mathrm{C}$ and Table 3 show the uterine and ovarian parameters in 16 patients undergoing pelvic ultrasound examination. Uterine length fell within normal centiles in all but 2 of 20 measurements from 12 patients aged
2-16 years, while in women aged $>20$ years, the values were consistent with the mean value of $67 \mathrm{~mm}$ in normal nulliparous women aged 25 years (19). However, a pubertal uterine configuration was found in only 2 girls aged $<15$ years, $2 / 9$ patients aged $15-20$ years and $3 / 5$ aged $>20$ years. FCR remained $\leq 1$ in 11/26 measurements in 11 patients aged $>15$ years, compared with $>1$ in all normal Scottish girls by this age (18). Endometrial thickness was detected in 15 of 44 examinations in 14 patients aged $\geq 11$ years, median (range) 1 (1-4.6) $\mathrm{mm}$.

Ovarian volumes up to 15 years were within the normative Griffin et al. centiles with one exception (Fig. 1B and C), with mean ovarian volumes 1.95 (B1), 3.3 (B2-3) and $5.3 \mathrm{~mL}$ (B4-5) similar to normative data. However, the maximum count of follicles measuring $2-10 \mathrm{~mm}$ never exceeded 6 at any age (Table 3) while follicles of $>10 \mathrm{~mm}$ were seen in only three patients.

\section{Biochemistry}

Basal LH was at or below the limit of detection for $13 / 20$ patients aged 2-4.9 and 5-10.9 years, with no difference between mean basal and stimulated LH between patients and controls at B1 (Table 4 and Supplementary Fig. 1A, B, see section on supplementary materials given at the end of this article).

Basal FSH was always detectable in patients aged 2-4.9 years, but at or below the limit of detection in 5/14 patients aged 5-10.9 years. Mean basal and peak FSH were significantly lower in the 5-10.9 age band than controls: 1.3 (1.46) vs $2.2(0.89) \mathrm{U} / \mathrm{L}(P=0.03) ; 5.98$ (1.58) vs 12.7 (3.65) $\mathrm{U} / \mathrm{L}(P=0.001)$. After 11 years no significant differences were found, either for subjects still at B1, or at B2-5. Basal FSH was $<10 \mathrm{U} / \mathrm{L}$ in all except in two patients: $14.1 \mathrm{U} / \mathrm{L}$ in a 46.8-year-old woman and basal/peak 11.4/51.2 U/L in a girl aged 2.1 years.Oestradiol values were undetectable in all but 2 patients aged $<11$ years. In patients aged 11-20 years, oestradiol was undetectable in three, median (range) 129 (70-520) $\mathrm{pmol} / \mathrm{L}$ in 16.

\section{Treatment}

Two patients received a single course of norethisterone, 5 mg daily for 5 days, for breakthrough bleeding. A further two received monthly norethisterone for 4 and 15 months before starting oestrogen treatment.

By the end of the study period, only 5 of the 24 patients with primary amenorrhoea aged > 14 years had been treated with oestrogen: one with oestradiol valerate+medroxyprogesterone as a 3-monthly cycle, one with Loestrin 20 (ethinylestradiol $20 \mathrm{mcg}$ and

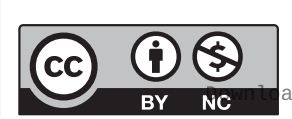

This work is licensed under a Creative Commons Attribution-NonCommercial 4.0 International License. ded from Bioscientifica.com at 04/26/2023 04:25:17AM via free access 
Table 2 Background information on 93 patients with Prader-Willi syndrome (PWS) seen at the Glasgow clinic between 1991 and 2019. Median (minimum-maximum) values are given with number of patients $(n=)$. See text for information on growth hormone status and treatment.

Number of patients
Birth year (range)
Died
Lost to follow-up
Age on 1 January 2020 (excluding deaths and patients lost to
follow-up)
Median (range) duration of follow-up (excluding 15 patients
seen $\leq 3$ occasions)
Cause of PWS ( $n=88$ )
Deletion
Disomy (unspecified)
Heterodisomy
Isodisomy
Imprinting defect
Translocation
No defect found
Tested elsewhere
Birthweight (kilograms)
Gestation (weeks)
Obesity status at last review $(n=87$ )
Non obese (BMl $<91$ st centile)
Overweight (BMI 91 st-98th centile)
Obese (BMI > 98th centile)
Morbidly obese (BMl $>40 \mathrm{~kg} / \mathrm{m}^{2}$ )
Psychiatric problems recorded in patients $>13$ years $(n=72$ )
Anxiety/obsessive compulsive
Depression
Psychosis/bipolar disorder
Marked aggression
Antisocial behaviour towards animals

norethisterone $1 \mathrm{mg}$ ) aged 19.5 years (stopped after 6 months owing to weight gain), one with ethinyl oestradiol from 17.4 to 22.4 years, another with ethinyl oestradiol from 16.4 years followed by loestrin 20 at 24 years, and one with oestradiol valerate $1 \mathrm{mg}$ from 17.9 years.

\section{Gonadal status males}

\section{Clinical features}

Unstretched penile length at birth was recorded in 23/56 boys as: $<2 \mathrm{~cm}(n=3), 2.1-3 \mathrm{~cm}(n=17)$ and $>3 \mathrm{~cm}(n=3)$. One or both testes were undescended in 54 patients (bilateral in 45), with normal descent in 2 . Initial position of the left/right testis was documented as abdominal $(n=8 / 6)$, inguinal canal $(n=11 / 9)$, external inguinal ring $(n=8 / 7)$, scrotal $(n=2 / 2)$, not specified $(n=17 / 22)$ (Fig. 2$)$.

Forty-four patients underwent orchidopexy, mean (s.D.) age at first surgery being $8.8(5.6)$ years $(n=24)$ prior

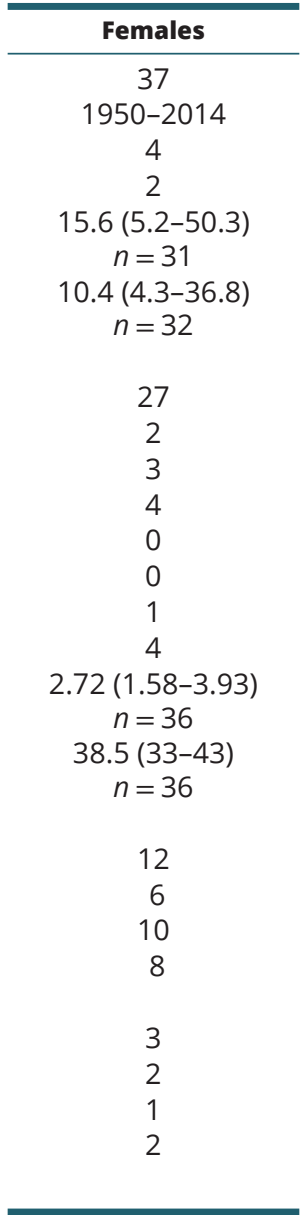

\begin{tabular}{c}
\hline All patients \\
\hline 93 \\
$1950-2016$ \\
11 \\
10 \\
$19.3(3.1-50.3)$ \\
$n=72$ \\
$11.2(1.2-40.8)$ \\
$n=78$
\end{tabular}

to 2000 and $2.0(0.7)$ years from 2000 to $2016(n=15)$. Of the remaining patients, one underwent bilateral orchidectomy elsewhere aged 19.7 years, four older patients were never operated on, surgery was pending in one, surgery not required in three, no information available in one.

Of 25 patients receiving twice-weekly hCG courses, only three showed testicular descent - bilateral descent from the inguinal position after 1000 units for 4 weeks in one boy (post-hCG testosterone unavailable); unilateral descent from the inguinal and external ring in two patients receiving 1000 units for 3 weeks (post-hCG testosterone $21.8 \mathrm{nmol} / \mathrm{L}$ and unavailable, respectively).

Figure 2 shows that orchidopexy was successful in 31 patients ( 8 unilateral), unsuccessful in 7 ( 2 unilateral) and partially successful in 8 (one viable testis brought into scrotum). The boys with failed bilateral orchidopexy were born between 1978 and 1987, age at operation https://ec.bioscientifica.com https://doi.org/10.1530/EC-21-0277 (c) 2021 The authors Published by Bioscientifica Ltd
This work is licensed under a Creative Commons Attribution-NonCommercial 4.0 International License. ded from Bioscientifica.com at 04/26/2023 04:25:17AM via free access 
A

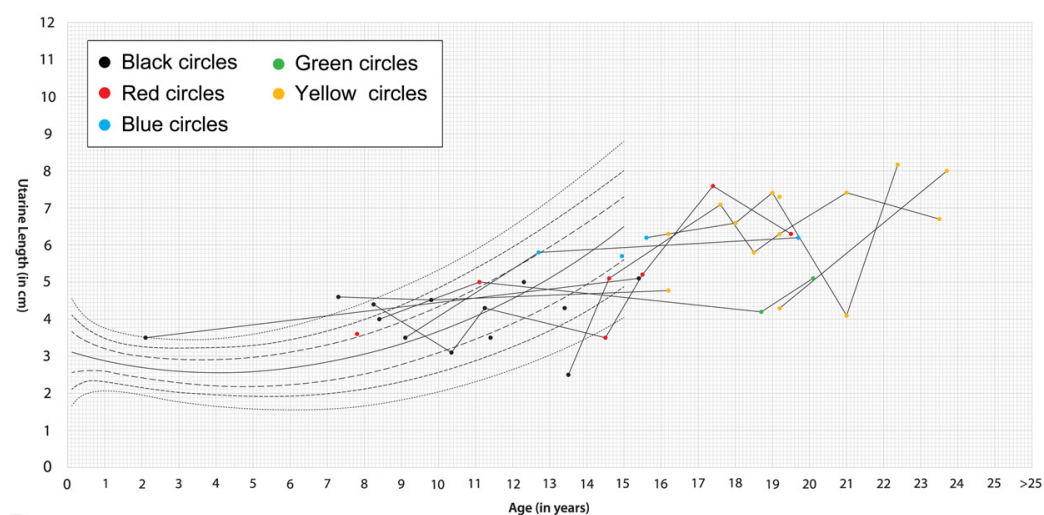

\section{B}

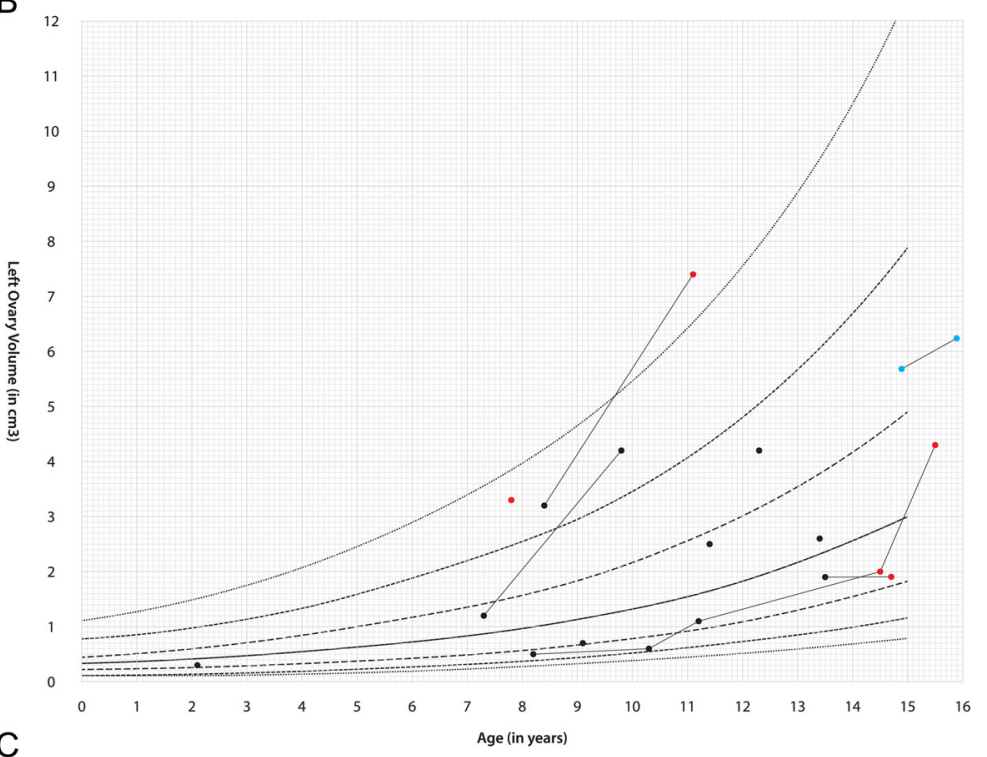

C

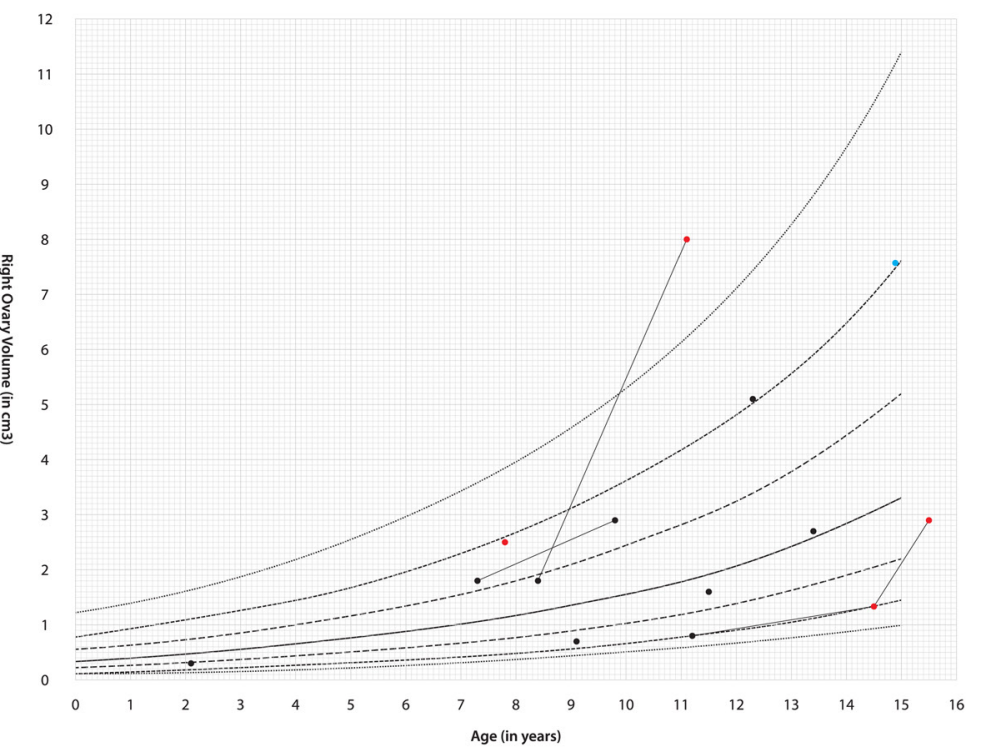

Figure 1

Uterine length (A), left ovarian volume (B) and right ovarian volume (C) in 16 females with Prader-Willi syndrome undergoing pelvic ultrasound examination, colour-coded according to breast stage: $\mathrm{B} 1=$ black circles, B2 = red circles, B3 = blue circles, B4 = green circles, B5 = yellow circles and plotted onto the normative centile charts of Griffin et al. (13). https://ec.bioscientifica.com

https://doi.org/10.1530/EC-21-0277 (c) 2021 The authors Published by Bioscientifica Ltd Attribution-NonCommercial 4.0 International License. ded from Bioscientifica.com at 04/26/2023 04:25:17AM via free access 
Table 3 Pelvic ultrasound findings showing one point per patient per age band. Median (minimum-maximum) values are given with number of patients $(n=)$. See reference 17 for normative data in girls aged $<15$ years. Uterine shape is denoted as infantile (I), cylindrical (C) or pubertal (P).

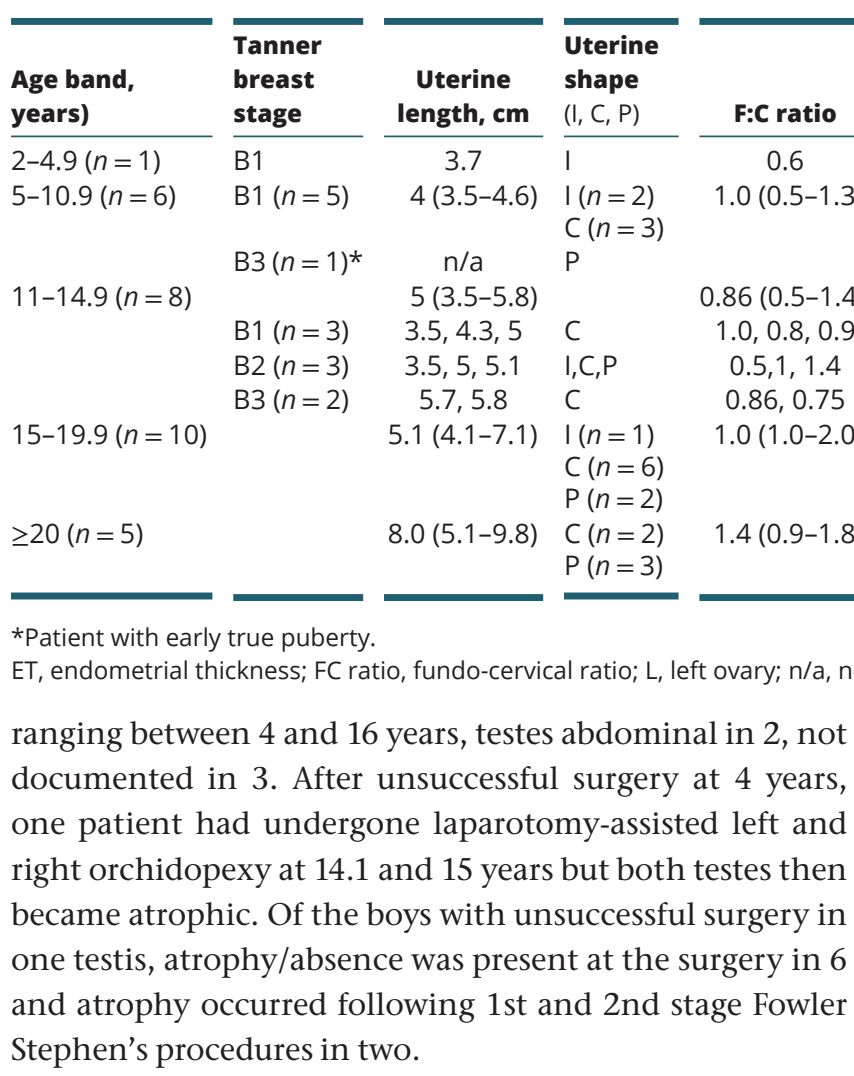

\section{Pubertal development}

Data were available in 37 boys aged > 11 years on 1 January 2020. Fourteen boys had not progressed beyond G1 prior to

\begin{tabular}{|c|c|c|c|c|}
\hline ET, mm & $\begin{array}{l}R \text { ovary vol, } \\
\mathrm{mL}\end{array}$ & $\begin{array}{l}R \text { ovary no. } \\
\text { of follicles } \\
2-10 \mathrm{~mm}\end{array}$ & $\begin{array}{l}\text { L ovary vol, } \\
\text { mL }\end{array}$ & $\begin{array}{l}\text { L ovary no. } \\
\text { of follicles } \\
2-10 \mathrm{~mm}\end{array}$ \\
\hline - & 0.3 & & 0.3 & $\mathrm{~ns}=1$ \\
\hline $1(n=1)$ & $1.8(0.7-2.5)$ & $\mathrm{ns}=5$ & $1.2(0.2-3.3)$ & $\mathrm{ns}=3$ \\
\hline
\end{tabular}

$2.7(0.8-7.6)$

$\begin{array}{lllll}1(n=1) & 1.6,2.7,5.1 & \mathrm{~ns}, 0,4 & 2.5,2.6,4.2 & \mathrm{~ns}, 0,5 \\ 1(n=1) & 1.4,7,0.8 & \mathrm{~ns}, 4,0 & 2,7.4,1.9 & \mathrm{~ns}, 4,0\end{array}$

7.6, nv 3, nv

$3(1-4.6) \quad 2.4(1-4.9) \quad 2(n=1) \quad 2.3(1-7.1) \quad 1,2(n=2)$

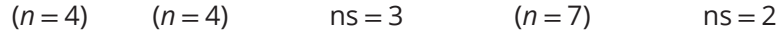

$\mathrm{nv}(n=3)$

$\mathrm{nv}(n=4)$

$(1-2)$

$n=3$

$9.8(3.1-14.2)$

$1-5(n=3)$

$\mathrm{ns}(n=1)$

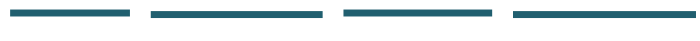




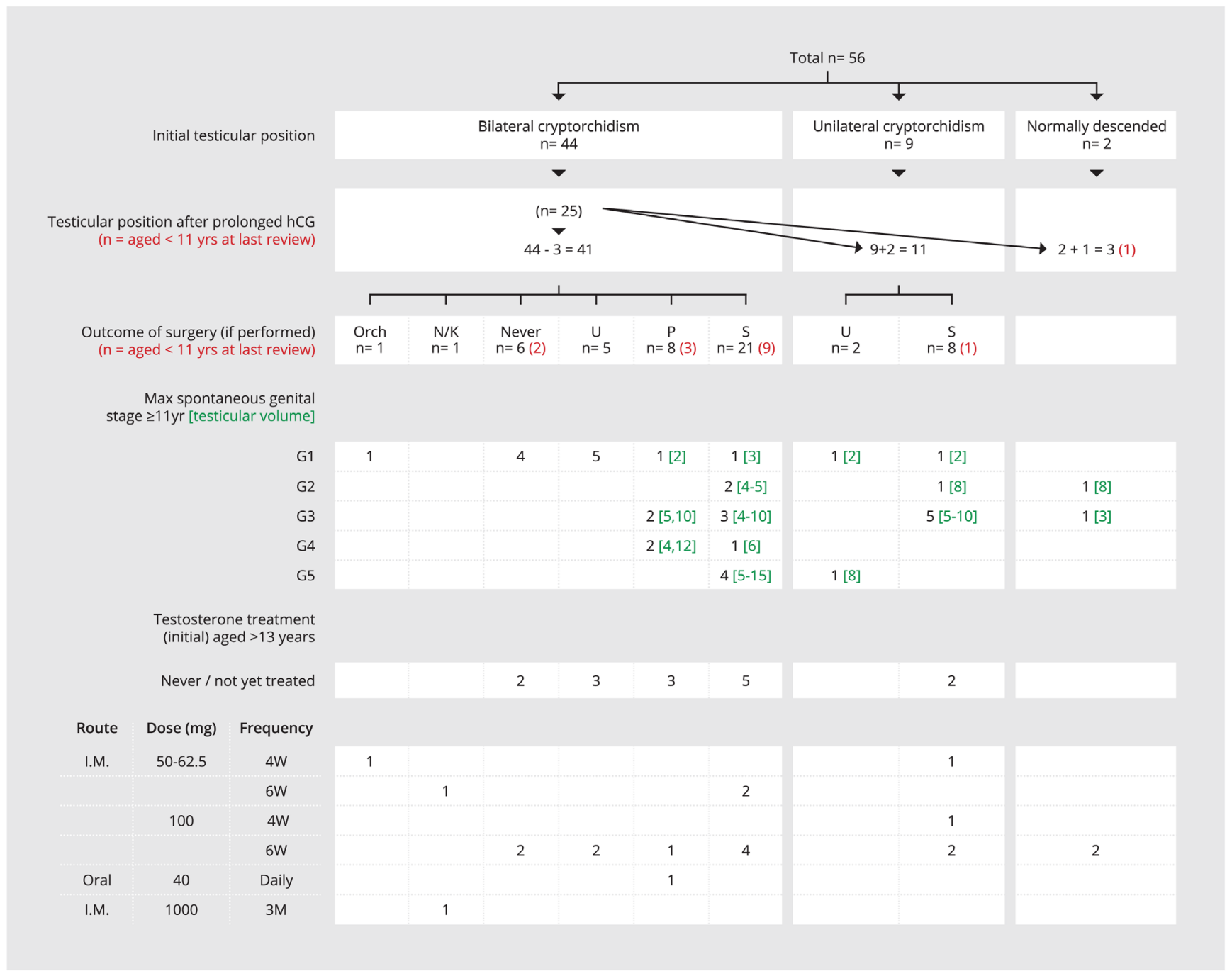

\section{Figure 2}

Gonadal status in 56 males with Prader-Willi syndrome in relation to initial testicular position, response to treatment with human chorionic gonadotrophin (hCG), outcome after surgery (if performed), maximum spontaneous genital (G) stage of puberty aged $\geq 11$ years, and status regarding initial testosterone replacement. For hCG treatment, $n=$ refers to number of boys receiving pre-operative weekly hCG. $(n=)$ refers to boys aged $<11$ years at time of last clinic visit. Orch, orchidectomy; N/K, not known; $U$, unsuccessful orchidopexy; $\mathrm{P}$, partially successful orchidopexy (one viable testis in scrotum); S, successful orchidopexy; I.M., intramuscular.

years, testicular volumes $6(4-15) \mathrm{mL}$, including three who had had unsuccessful surgery in one testis.

At last review, 7 patients aged > 11 years were still at G1, 3 at G2, 14 (10 treated) at G3, 8 (7 treated) at G4 and 7 (3 treated) at G5. Testicular volumes in the 15 patients at G4 or G5 ranged between absent $(n=4), 1-2(n=1), 3-4$ $(n=6), 5-6(n=6), 8-10(n=5)$ and $12 \mathrm{~mL}(n=3)$ (no data for 5 testes). Pubic hair stage for patients at G4 and G5 was P4 $(n=3)$, P5 $(n=8)$, no data $(n=4)$

\section{Biochemistry}

LH and FSH data At $<2$ years, $\mathrm{LH}$ and FSH responses to GnRH appeared normal. From 2 to 10.9 years basal and stimulated gonadotrophins were lower cf controls, but not significantly (Table 5 and Supplementary Fig. 2A, B).

For patients aged $\geq 11$ years who were still at G1, and after excluding the anorchic patient, mean basal/peak gonadotrophins were not different from controls: $0.9 / 3.5$ $(n=18 / 12)$ vs $0.4 / 3.1(n=13)(P=0.12)$ for $\mathrm{LH}$ and $2.3 / 3.1$ vs $0.6 / 2.4(P=0.36)$ for FSH.

For patients at G2-5, basal and stimulated LH levels were non-significantly higher than controls: 2.43/25.4 ( $n=23 / 6)$ vs $1.49 / 14.4(n=14 / 14)$. However, FSH values were significantly higher: $12.3 / 27.3$ vs $3.25 / 6.26(P<0.001)$.

hCG, testosterone and inhibin B data Twelve patients, all born before 1986, received 15 hCG treat-

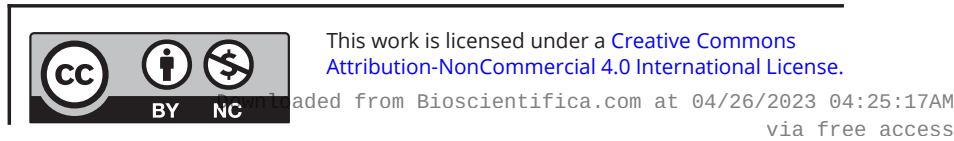


Table 5 Biochemical findings 38 of 56 male patients with Prader-Willi syndrome, showing one point per patient per age band. Median (range) values are shown. Testosterone values post hCG given to 16/19 patients prior to surgery and to 9 patients to test Leydig cell reserve are shown. Data does not include patients on testosterone therapy.

\begin{tabular}{|c|c|c|c|c|c|c|c|}
\hline Age band & Basal LH, U/L & Peak LH, U/L & Basal FSH, U/L & Peak FSH, U/L & Basal T, nmol/L & $\begin{array}{l}\text { Post hCG T, } \\
\text { nmol/L }\end{array}$ & Inhibin B, pg/mL \\
\hline $0-1.9$ & $\begin{array}{l}0.2(<0.2-2.8) \\
n=7\end{array}$ & $\begin{array}{l}15.1(0.6-46.9) \\
n=6\end{array}$ & $\begin{array}{l}1.3(<0.2-4.0) \\
n=7\end{array}$ & $\begin{array}{l}12.4(2.6-16.7) \\
n=6\end{array}$ & $\begin{array}{l}0.9(0.4-2.4) \\
n=4\end{array}$ & $\begin{array}{l}24.9(5.7-41.5) \\
n=6\end{array}$ & \\
\hline $2-4.9$ & $\begin{array}{l}0.2(<0.2-0.5) \\
n=5\end{array}$ & $\begin{array}{l}1.0,1.2 \\
n=2\end{array}$ & $\begin{array}{l}0.2(<0.2-1.7) \\
n=5\end{array}$ & $\begin{array}{l}(5,13.5) \\
n=2\end{array}$ & $\begin{array}{l}0.35(0.3-0.7) \\
n=6\end{array}$ & $\begin{array}{l}12.0 \\
n=1\end{array}$ & $\begin{array}{l}13.3,23.8 \\
n=2\end{array}$ \\
\hline $5-10.9$ & $\begin{array}{l}0.2(<0.2-1.9) \\
n=13\end{array}$ & $\begin{array}{l}1.45(<0.2-5.4) \\
n=10\end{array}$ & $\begin{array}{l}0.4(<0.2-2.3) \\
n=13\end{array}$ & $\begin{array}{l}4.5(2.1-9.3) \\
n=10\end{array}$ & $\begin{array}{l}(0.3-0.7) \\
14\end{array}$ & $\begin{array}{l}3.35(1.0-20.4) \\
n=6\end{array}$ & $\begin{array}{l}70 \\
n=1\end{array}$ \\
\hline $11-14.9$ & $\begin{array}{l}0.3(<0.2-5.0) \\
n=15\end{array}$ & $\begin{array}{l}4.1(<0.2-19.1) \\
n=7\end{array}$ & $\begin{array}{l}3.6(<0.2-20.9) \\
n=15\end{array}$ & $\begin{array}{l}3.7(1.6-23) \\
n=6\end{array}$ & $\begin{array}{l}2.0(0.3-8.4) \\
n=13\end{array}$ & $\begin{array}{l}8.3(7.7-26.8) \\
n=5\end{array}$ & $\begin{array}{l}14.7,22.7,59.8 \\
n=3\end{array}$ \\
\hline 15-19.9 & $\begin{array}{l}1.3(2.1) \\
0.85(<0.2-7.4) \\
n=18\end{array}$ & $\begin{array}{l}17.0(25.7) \\
10.1(<0.2-80.5) \\
n=9\end{array}$ & $\begin{array}{l}8.53(8.0) \\
7.6(<0.2-27.7) \\
n=18\end{array}$ & $\begin{array}{l}14.3(17.6) \\
11.4(<0.2-53.9) \\
n=9\end{array}$ & $\begin{array}{l}2.8(2.6) \\
1.8(0.3-10.8) \\
n=18\end{array}$ & $\begin{array}{l}5.4(5.47) \\
3.2(0.8-12.8) \\
n=6\end{array}$ & $\begin{array}{l}12.1,11.1,28.2, \\
67.3 \\
n=4\end{array}$ \\
\hline$\geq 20$ & $\begin{array}{l}1.6(1.56) \\
1.6(<0.2-4.1) \\
n=9^{a}\end{array}$ & $\begin{array}{l}0.2,0.2 \\
n=2\end{array}$ & $\begin{array}{l}7.8(9.1) \\
6.9(<0.2-27.1) \\
n=9^{a}\end{array}$ & $\begin{array}{l}0.2,0.5 \\
n=2\end{array}$ & $\begin{array}{l}2.7(2.1) \\
1.7(0.5-6.5) \\
n=10\end{array}$ & $\begin{array}{l}1.4 \\
n=1\end{array}$ & $\begin{array}{l}17.2,19.6,35.1 \\
35.4,44.4 \\
n=5\end{array}$ \\
\hline
\end{tabular}

${ }^{a}$ After excluding anorchic patient with LH 19.2 and FSH 65.2 U/L.

FSH, follicle-stimulating hormone; hCG, human chorionic gonadotrophin; LH, luteinising hormone; T, testosterone.

ments by daily injection over 4 (1-5) days in the dose of 5000 (50-6000) units at 13.9 (6.3-18.6) years. After excluding tests from 3 patients who showed no response -2 with severe hypogonadism (both failing to progress subsequently beyond G1) and 1 in whom non-response was considered spurious (patient subsequently progressing to G5), median (range) post-hCG testosterone was $7.7(1.9-26.8) \mathrm{nmol} / \mathrm{L}$.

Twenty-three patients received 24 hCG treatments as twice-weekly injections, duration 6 (2-6) weeks, dose 1500 (500-2000) at a significantly younger age, 7 (0.4-19.8) years (10 patients aged $<2$ years) $(P=0.038)$. After excluding two patients (one spurious non-response and one of the patients with severe hypogonadism), post-hCG testosterone was lower than with daily injections at 19 (12.92), $12(5.7-41.5) \mathrm{nmol} / \mathrm{L}(n=11)$ but the difference did not reach significance $(P=0.06)$.

Peak testosterone after hCG in subjects aged $<2$ years was consistent with intact Leydig cell function (Table 5). However, basal testosterone at G3-5 was $3.1(0.5-8.4) \mathrm{nmol} / \mathrm{L}(n=15)$, well below the adult reference range of $8-37.5 \mathrm{nmol} / \mathrm{L}$.

Inhibin B values, which were measured in 15 patients, were all detectable ( $>10 \mathrm{pg} / \mathrm{mL}$ ). However, all values were below the age-related reference ranges except in one boy aged 7.2 years (Table 5). Inhibin B values did not correlate with either basal FSH or Tanner stage, being no different in boys with FSH < 0.6 vs 1-12 U/L or pubertal stage G1 vs G2-5. There was also no correlation between inhibin $B$ and testicular volumes, for example, 13.3-70 pmol/L in three prepubertal boys with $2 \mathrm{~mL}$ testes, and 14.7-63.3 in 7 boys with testes 5-6 mL.

\section{Treatment}

Of 46 patients aged > 13 years on 1 January 2020, 24 had started testosterone therapy aged 16.8 (13.5-29.2) years, 19 had received no treatment, no information in 3 . All but two of the treated patients had been treated with combined testosterone esters, given as Sustanon, initial dose 50-62.5 $\mathrm{mg}(n=16)$ and $100 \mathrm{mg}(n=15)$ every 6 weeks $(n=14)$; maximal dose 50-62.5 $(n=2), 100(n=9), 125$ $(n=3)$ and 200-250 $\mathrm{mg}(n=8)$ every $2(n=2), 4(n=9)$, $6(n=11)$ and $12(n=1)$ weeks. Recent treatment details were not available in all patients aged $>16$ years who were under adult follow-up. Electronic clinical records indicated that treatment had been stopped in 4 due to behavioural concerns (Fig. 2).

\section{Discussion}

This series spans a 45-year period, the earliest patients being seen from 1974, thus providing valuable longitudinal information including previously unpublished pelvic ultrasound data. There is, however, the disadvantage of incomplete patient data and, intrinsic to a study of this nature, inconsistent protocols and management. Specifically, the study period conceals trends in clinical practice including a reduction in age at diagnosis and first surgery, differing hCG regimens, and increased use
This work is licensed under a Creative Commons Attribution-NonCommercial 4.0 International License. ed from Bioscientifica.com at 04/26/2023 04:25:17AM via free access 
of GH. Hormone assays varied during the study period, with relatively insensitive gonadotrophin cut-offs until 2014. Another methodological variable was breast staging in female patients. Distinguishing between true breast development and adipose tissue in females with and without PWS can be difficult. While stages 4 and 5 breast development were diagnosed with confidence by our dedicated auxologist and specialist nurse, distinction between B1, B2 and B3 in obese patients was, unavoidably, a matter of subjective (albeit expert) judgement.

In females, the clinical profile is of partial hypogonadism, most but not all girls entering puberty spontaneously, less than half achieving full adult breast development, and primary or oligo-amenorrhoea in all.

In this study, we present pelvic ultrasound in PWS for the first time. This method is well-established in paediatrics for assessing and measuring uterine shape and configuration - indices of oestrogen secretion; ovarian volume and follicular number and size - indices of gonadotrophin stimulation.

We found that uterine length was normal up to the age of 16 (Fig. 1A), but the mature, 'pear-shaped' configuration seen in normal Scottish girls by 15 years (18) was usually not achieved (Table 3). Endometrial thickness, another index of oestrogen secretion, was usually not detected in patients over 11 years, with a median value of only $1 \mathrm{~mm}$, well below the normative mean of $4.5 \pm 3.7 \mathrm{~mm}$ (19).

Gonadotrophin secretion was sufficient to result in normal ovarian volumes (Fig. 1B and C), but not the normal antral follicle counts of 6.2-33.2 reported in healthy 16-year-old by transvaginal ultrasound examination (23). The gonadotrophin profile was unremarkable, apart from slightly lower FSH levels in the 5-10.9 age groups. Oestradiol levels were reduced from adolescence onwards, values never $>600 \mathrm{pmol} / \mathrm{L}$ in patients aged $>15$ years. These data are consistent with previous reports $(8,11,15)$.

In males, the clinical profile is again consistent with previous work $(7,8,9,10,11,12)$. Small penile size at birth is common but micropenis is rare $(8,13)$, and cryptorchidism is almost constant. Outcome after orchidopexy was inferior compared with the general population, partly attributable to pre-existing hypoplasia/atrophy (24). Untreated or failed bilateral cryptorchidism resulted in pubertal failure. However, males with failed unilateral orchidopexy but a contralateral testis in place fared as well at puberty as those with bilateral descent (see below). Thus, if one viable testis is in the scrotum in PWS, extensive efforts to salvage a problematic testis with re-do orchidopexy appear unjustified.

Preoperative weekly hCG treatment was relatively unsuccessful in our experience, with descent in only $4 / 46$
(8\%) testes vs 4/29 (14\%) in the study of Bakker et al. study (25). Further study using internationally agreed protocols is required to define the role of hCG administration in PWS, regarding both scrotal descent and improving outcome in intra-abdominal cryptorchidism.

Apart from the boys with failed/untreated cryptorchidism, a small number of patients remained at G1 despite successful unilateral or bilateral orchidopexy. Boys who entered puberty spontaneously had reduced testicular volumes, most showing mid-pubertal arrest as previously reported $(4,7,13)$ but some reaching $G 4 / 5$. The reduction in testicular volume seen in PWS is attributable to reduced seminiferous tubule tissue (10), demonstrable in subjects as young as 2 years (25). Of note, neither spontaneous/hCGinduced testicular descent seemed to protect against midpubertal arrest, three boys arresting at G2-3 comprising two with normally descended testes (one post-hCG) and one with unilateral descent post-hCG. By contrast, three boys who reached G4/5 had only one testis successfully treated.

The biochemical profile was of normal basal and stimulated gonadotrophins and testosterone response to hCG between 0 and 2 years, in keeping with intact minipuberty $(10,13)$. Gonadotrophins were unremarkable in prepubertal boys. Supplementary Figure $2 \mathrm{~b}$ shows the well-described FSH elevation seen from adolescence (7, $8,9,10,11,12$ ) but this was confined to boys showing spontaneous puberty. Testosterone levels were subnormal from adolescence onwards while inhibin B in a relatively small cross section of patients was almost uniformly low. Testosterone data post-hCG treatment were variable but an adequate or good response was usual on both daily and weekly regimes. The higher mean testosterone levels in patients receiving weekly rather than daily hCG might reflect greater response to prolonged stimulation but could also be explained by greater Leydig responsiveness in younger subjects.

Possible mechanisms for the hypogonadism in PWS are the subject of debate. Hypogonadotrophic hypogonadism would seem the most likely explanation, given the known hypothalamic dysfunction in PWS. However, basal gonadotrophin levels in infancy and childhood are usually unremarkable in both sexes, even with cut-offs as sensitive as $<0.1 \mathrm{U} / \mathrm{L}(9,15)$. This could reflect the limited ability of basal/stimulated gonadotrophin measurement in detecting dysregulation of hypothalamic GnRH secretion. Detection of primary hypogonadism also poses problems. Raised FSH levels are only informative when hypothalamo-pituitary function is sufficiently intact and not when a concurrent central defect is present. Inhibin B has been used as an indicator 
of gonadal impairment in PWS $(7,8,9,12,26)$ but low inhibin B levels are also found in hypogonadotrophic hypogonadism affecting both sexes $(27,28)$. The failure in our study to correlate inhibin B levels with FSH, Tanner stage, or testicular volume may reflect its limitations in separating the effect of central, peripheral, or combined hypogonadism.

In female PWS, the pattern of normal ovarian volumes, normal AMH $(14,15)$ but the low follicular count is evocative of central hypogonadism in childhood and adolescence. However, an accompanying peripheral defect cannot be excluded in our female cohort, and it is likely that the unrecordable inhibin B levels $(<10 \mathrm{pg} / \mathrm{mL})$ reported in older PWS females do reflect primary gonadal impairment (26).

In males, hypogonadotrophic hypogonadism is suggested by cryptorchism with small penis at birth, nonelevated gonadotrophins, and the failure of some patients to enter puberty spontaneously. An additional primary defect is also evident from FSH elevation in pubertal males and from the known histological abnormalities $(10,24)$.

Given that hypogonadism is invariable in PWS, it is paradoxical that no clear treatment guidelines have been developed. In our series, some but not all boys received a variety of regimes, usually in the form of 4-6 weekly intramuscular testosterone, on an individual basis. The underlying reasons for such undertreatment reflect the wider health concerns over PWS which include death from morbid obesity and the fear of sex steroid replacement exacerbating existing behavioural problems.

Regarding the concern over obesity, our study shows the significant mortality in PWS and that, consistent with data from France (29) and the United States (30), almost all the adult deaths were obesity-related, with a median age of 26 years. However, in contrast to the French study (29), only two deaths in our series occurred in patients aged below 18 years, with no deaths recorded in patients under 2 years - a discrepancy which could reflect problems with ascertainment since our earliest patients were born in the 1970s when some subjects with PWS could have died undiagnosed. However, there are no data to show that appropriate sex steroid replacement therapy exacerbates morbid obesity in PWS.

Regarding the risk of sex steroid exacerbating behaviour problems in PWS, the comprehensive review of Noordam et al. points to the lack of scientific evidence for any detrimental (31). Of 27 males described by these authors, all 7 in whom androgen replacement was discontinued for behavioural reasons had pre-existing problems. Accordingly, the authors recommend inducing puberty at the normal dose and the normal age in PWS, administering oestradiol $0.5 \mathrm{mg}$ daily from 11 to 12 years in girls, and testosterone enanthate $100 \mathrm{mg} / 4$ weeks from 13 to 14.5 years in boys (31).

Furthermore, it is important to consider the potential benefits, not only of growth hormone replacement therapy (32) but also sex steroid replacement therapy on metabolic health and body composition in PWS (33). Kido et al. in an adult study of 22 PWS males given $125 \mathrm{mg}$ of intramuscular testosterone monthly for 2 years showed improvement in body fat, lean muscle mass and bone mineral density with no change in Modified Overt Aggression Scale (MOAS) behaviour scores (33). It is, therefore, possible that sex hormone replacement might actually reduce the risk of obesity-related death in PWS. Moreover, sex hormone replacement could positively influence behaviour, mental health and quality of life in PWS, as has been shown with transdermal testosterone therapy in hypogonadal men (34).

We believe that the question of sex steroid treatment and its effect on behaviour in PWS should be resolved by randomised, placebo-controlled crossover studies. Given the ethical and practical concerns of giving intramuscular placebo injections, we advocate studies examining oral or transdermal testosterone and oestrogen replacement. This approach, when combined parental recording the severity and frequency of behavioural events would provide the evidence needed to inform future management.

\section{Supplementary materials}

This is linked to the online version of the paper at https://doi.org/10.1530/ EC-21-0277.

\section{Declaration of interest}

The authors declare that there is no conflict of interest that could be perceived as prejudicing the impartiality of the research reported.

\section{Funding}

This work did not receive any specific grant from any funding agency in the public, commercial, or not-for-profit sector.

\section{Acknowledgements}

The authors wish to honour the memory of Ms Wendy Paterson, who recorded the clinical, biochemical and pelvic ultrasound data for this study until her untimely death in 2012. Without her faithful and painstaking work, the authors would have been unable to publish the results of this long-term study. We thank Dr Patricia Crofton for kindly carrying out the inhibin B analysis at the Royal Hospital for Sick Children, Edinburgh.

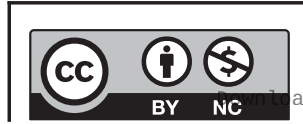

This work is licensed under a Creative Commons Attribution-NonCommercial 4.0 International License. ed from Bioscientifica com at 04/26/2023 04:25:17Am via free access 
The authors also gratefully acknowledge the generous help and advice given by Prof Tim Cole, Prof Richard Anderson, Prof Regis Coutant, Dr Jane McNeilly and Dr Peter Galloway. The authors thank Mr Hamish Donaldson for assisting with data analysis, and Mr Mark Whittington for preparing the Figures. Finally, the authors pay tribute to the patients and families with PWS who have attended the Glasgow clinic.

\section{References}

1 Cassidy SB, Schwartz S, Miller JL \& Driscoll DJ. Prader-Willi syndrome. Genetics in Medicine 201214 10-26. (https://doi.org/10.1038/ gim.0b013e31822bead0)

2 Buiting K, Saitoh S, Gross S, Dittrich B, Schwartz S, Nicholls RD \& Horsthemke B. Inherited microdeletions in the Angelman and PraderWilli syndromes define an imprinting centre on human chromosome 15. Nature Genetics 19959 395-400.

3 Charrow J, Balkin N \& Cohen MM. Translocations in PraderWilli syndrome. Clinical Genetics 198323 304-307. (https://doi. org/10.1111/j.1399-0004.1983.tb01881.x)

4 Holm VA, Cassidy SB, Butler MG, Hanchett JM, Greenswag LR, Whitman BY \& Greenberg F. Prader-Willi syndrome: consensus diagnostic criteria. Pediatrics 199391 398-402.

5 Donaldson MDC, Chu CE, Cooke A, Wilson A, Greene SA \& Stephenson JBP. The Prader-Willi syndrome. Archives of Disease in Childhood 1994 70 58-63. (https://doi.org/10.1136/adc.70.1.58)

6 Goldstone AP, Holland AJ, Hauffa BP, Hokken-Koelega AC \& Tauber M. Speakers, contributors at the second expert meeting of the comprehensive care of patients with PWS. Recommendations for the diagnosis and management of Prader-Willi syndrome. Journal of Clinical Endocrinology and Metabolism 200893 4183-4197. (https://doi. org/10.1210/jc.2008-0649)

7 Eiholzer U, Allemand D, Rousson V, Schlumpf M, Gasser T, Girard J, Gruters A \& Simoni M. Hypothalamic and gonadal components of hypogonadism in boys with Prader-Labhart-Willi syndrome. Journal of Clinical Endocrinology and Metabolism 200691 892-898. (https://doi org/10.1210/jc.2005-0902)

8 Hirsch HJ, Eldar-Geva T, Bennaroch F, Pollak Y \& Gross-Tsur V. Sexual dichotomy of gonadal function in Prader-Willi syndrome from early infancy through the fourth decade. Human Reproduction 201530 2587-2596. (https://doi.org/10.1093/humrep/dev213)

9 Siemensma EP, de Lind van Wijngaarden RF, Otten BJ, de Jong FH $\&$ Hokken-Koelega AC. Testicular failure in boys with Prader-Willi syndrome: longitudinal studies of reproductive hormones. Journal of Clinical Endocrinology and Metabolism 201297 E452-E459. (https://doi. org/10.1210/jc.2011-1954)

10 Matsuyama S, Matsui F, Matsuoka K, Iijima M, Takeuchi M, Ida S, Matsumoto F \& Mizokami A. Gonadal function and testicular histology in males with Prader-Willi syndrome. Endocrinology, Diabetes and Metabolism 201830 e00049. (https://doi.org/10.1002/edm2.49)

11 Crino A, Schiaffini R, Ciampalini P, Spera S, Beccaria L, Benzi F, Bosio L, Corrias A, Gargantini L, Salvatoni A, et al. Hypogonadism and pubertal development in Prader-Willi syndrome. European Journal of Pediatrics 2003162 327-333. (https://doi.org/10.1007/s00431-002-1132-4)

12 Radicioni AF, Di Giorgio G, Grugni G, Cuttini M,Losacco V, Anzuini A, Spera S, Marzano C, Lenzi A, Cappa M, et al. Multiple forms of hypogonadism of central, peripheral or combined origin in males with Prader-Willi syndrome. Clinical Endocrinology 201276 72-77. (https:// doi.org/10.1111/j.1365-2265.2011.04161.x)

13 Fillion M, Deal CL \& Van Vliet G. Normal minipuberty of infancy in boys with Prader-Willi syndrome. Journal of Pediatrics 2006149 874-876. (https://doi.org/10.1016/j.jpeds.2006.08.077)

14 Eldar-Geva T, Hirsch HJ, Benarroch F, Rubinstein O \& Gross-Tsur V. Hypogonadism in females with Prader-Willi syndrome from infancy to adulthood: variable combinations of a primary gonadal defect and hypothalamic dysfunction. European Journal of Endocrinology 2010162 377-384. (https://doi.org/10.1530/EJE-09-0901)

15 Siemensma EP, van Alfen-van der Velden AAEM, Otten BJ, Laven JS \& Hokken-Koelega AC. Ovarian function and reproductive hormone levels in girls with Prader-Willi syndrome: a longitudinal study. Journal of Clinical Endocrinology and Metabolism 201297 E1766-E1773. (https:// doi.org/10.1210/jc.2012-1595)

16 Chu CE, Cooke A, Stephenson JBP, Tolmie JL, Clarke B, ParryJones WL, Connor JM \& Donaldson MDC. Diagnosis in Prader-Willi syndrome. Archives of Disease in Childhood 199471 441-442. (https:// doi.org/10.1136/adc.71.5.441)

17 Tanner JM. Growth at Adolescence, 2nd ed. Oxford: Blackwell Scientific Publications, 1962.

18 Griffin IJ, Cole TJ, Duncan KA, Hollman AS \& Donaldson MDC. Pelvic ultrasound measurements in normal girls. Acta Paediatrica 199584 536-543. (https://doi.org/10.1111/j.1651-2227.1995.tb13689.x)

19 Verguts J, Ameve L, Bourne T \&Timmerman D. Normative data for uterine size according to age and gravidity and possible role of the classical golden ratio. Ultrasound in Obstetrics and Gynecology 201342 713-717. (https://doi.org/10.1002/uog.12538)

20 Gilligan LA, Trout AT, Schuster JG, Schwartz BI, Breech LL, Zhang B \& Towbin AJ. Normative values for ultrasound measurements of the female pelvic organs throughout childhood and adolescence. Pediatric Radiology 201949 1042-1050. (https://doi.org/10.1007/s00247-019-04419-z)

21 Crofton PM, Evans AEM, Groome NP, Taylor MRH, Holland CV \& Kelnar CJH. Dimeric inhibins in girls from birth to adulthood: relationship with age, pubertal stage, FSH and oestradiol. Clinical Endocrinology 200256 223-230. (https://doi.org/10.1046/j.03000664.2001.01449.x)

22 Çizmecioğlu FM, Jones JH, Paterson WF, Kherra S, Kourime M, McGowan R, Shaikh MG \& Donaldson M. Neonatal features of the Prader-Willi syndrome; the case for making the diagnosis during the first week of life. Journal of Clinical Research in Pediatric Endocrinology 201810 264-273. (https://doi.org/10.4274/jcrpe.0029)

23 La Marca A, Spada E, Sighinolfi G, Argento C, Tirelli A, Giulini S, Milani S \& Volpe A. Age-specific nomogram for the decline in antral follicle count throughout the reproductive period. Fertility and Sterility 201195 684-688. (https://doi.org/10.1016/j. fertnstert.2010.07.1069)

24 Pacilli M, Heloury Y, O’Brien M, Lionti T, Rowell M \& Hutson J. Orchidopexy in children with Prader-Willi syndrome: results of a longterm follow-up study. Journal of Pediatric Urology 201814 63.e1-63.e6. (https://doi.org/10.1016/j.jpurol.2017.10.003)

25 Bakker NE, Wolffenbuttel KP, Looijenga LH \& Hokken-Koelega AC. Testes in infants with Prader-Willi syndrome: human chorionic gonadotropin treatment, surgery and histology. Journal of Urology 2015 193 291-298. (https://doi.org/10.1016/j.juro.2014.07.113)

26 Gross-Tur V, Hirsch HJ, Benarroch F \& Eldar-Geva T. The FSH-inhibin axis in Prader-Willi syndrome: heterogeneity of gonadal dysfunction. Reproductive Biology and Endocrinology 2012 10 39. (https://doi. org/10.1186/1477-7827-10-39)

27 Corvest V, Lemaire P, Brailly-Tabard S \& Brauner R. Puberty and inhibin B in 35 adolescents with pituitary stalk interruption syndrome. Frontiers in Pediatrics 20208 304. (https://doi.org/10.3389/ fped.2020.00304)

28 Coutant R, Biette-Demeneix E, Bouvattier C, Bouhours-Nouet N, Gatelais F, Dufresne S, Rouleau S \& Lahlou N. Baseline inhibin $\mathrm{B}$ and anti-mullerian hormone measurements for diagnosis of hypogonadotropic hypogonadism (HH) in boys with delayed puberty. Journal of Clinical Endocrinology and Metabolism 201095 5225-5232. (https://doi.org/10.1210/jc.2010-1535)

29 Alfaro DLP, Lemoine P, Ehlinger V, Molinas C, Diene G, Valette M, Pinto G, Coupaye M, Poitou-Bernert C, Thuilleaux D, et al. Causes of death in Prader-Willi syndrome: lessons from 11 years' experience of https://ec.bioscientifica.com https://doi.org/10.1530/EC-21-0277 (c) 2021 The authors Published by Bioscientifica Ltd

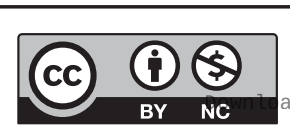

This work is licensed under a Creative Commons Attribution-NonCommercial 4.0 International License. ded from Bioscientifica, com at 04/26/2023 04:25:17AM 
a national reference center. Orphanet Journal of Rare Diseases 201914 238. (https://doi.org/10.1186/s13023-019-1214-2)

30 Butler MG, Manzardo AM, Heinemann J, Loker C \& Loker J. Causes of death in Prader-Willi syndrome: Prader-Willi Syndrome Association (USA) 40-year mortality survey. Genetics in Medicine 201719 635-642. (https://doi.org/10.1038/gim.2016.178)

31 Noordam C, Höybye C \& Eiholzer U. Prader-Willi syndrome and hypogonadism: a review article. International Journal of Molecular Sciences 202122 2705. (https://doi.org/10.3390/ijms22052705)

32 Damen L, Grootjen LN, Donze SH, Juriaans AF, de Graaff LCG, van der Velden JAEM \& Hokken-Koelega ACS. Three years of growth hormone treatment in young adults with Prader-Willi syndrome previously treated with growth hormone in childhood: effects on glucose homeostasis and metabolic syndrome. Clinical Endocrinology 202093 439-448. (https://doi.org/10.1111/cen.14274)
33 Kido Y,Sakazume S, Abe Y, Oto Y, Itabashi H, Shiraishi M, Yoshino A, Tanaka Y, Obata K, Murakami N, et al. Testosterone replacement therapy to improve secondary sexual characteristics and body composition without adverse behavioral problems in adult male patients with Prader-Willi syndrome: an observational study. American Journal of Medical Genetics: Part A 2013 161A 2167-2173. (https://doi.org/10.1002/ ajmg.a.36048)

34 Wang C, Swerdloff RS, Iranmanesh A, Dobs A, Snyder PJ, Cunningham G, Matsumoto AM, Weber T, Berman N \& Testosterone Gel Study Group. Transdermal testosterone gel improves sexual function, mood, muscle strength, and body composition in hypogonadal men. Journal of Clinical Endocrinology and Metabolism 200085 2839-2853. (https://doi.org/10.1210/ jcem.85.8.6747)

Received in final form 5 August 2021

Accepted 11 August 2021

Accepted Manuscript published online 12 August 2021
This work is licensed under a Creative Commons Attribution-NonCommercial 4.0 International License. ded from Bioscientifica.com at 04/26/2023 04:25:17AM via free access 